\title{
Low Cost Improvement of Coastal Douglas-fir (Pseudotsuga menziesii var. menziesii (Mirb.) Franco) By Application of The Breeding Seed Orchard Approach in Denmark
}

\author{
By J. K. HANSEN ${ }^{1)}$, H. WeLlendorF and E. D. KJÆR \\ Danish Centre for Forest, Landscape and Planning, The Royal Veterinary and Agricultural University, Denmark. \\ Hørsholm Kongevej 11, DK-2970 Hørsholm.
}

(Received 20 $0^{\text {th }}$ May 2005)

\begin{abstract}
An evaluation of a seedling seed orchard in Denmark of Coastal Douglas-fir showed variation between open pollinated families in their susceptibility to windthrow, height and diameter growth, stem straightness, number of forks at age 10 and bud burst at age 9. Individual narrow-sense heritability was 0.63 for bud burst, 0.40 for height and diameter, respectively, 0.48 for stem straightness, 0.20 for number of forks and 0.17 for windthrow susceptibility. Fast growing families were characterised by late bud burst, and poorer stem straightness. The approach of using seedling seed orchards in Denmark is discussed in relation to genetic gains, genetic diversity and risk of inbreeding. Predicted gains concerning a reduction of windthrow susceptibility were poor due to low genetic variability. In multi-trait selection scenarios aiming to improve growth, stem straightness and reducing windthrow susceptibility, the approach of using seedling seed orchards demonstrated that it might be possible to obtain gains in height above $5 \%$ combined with significant improvements of stem straightness while retaining an effective population size above 50 .
\end{abstract}

Key words: heritability estimates, genetic correlation, growth, stem straightness, forking, windthrow, bud burst, genetic diversity, genetic gain.

\section{Introduction}

In Danish forestry, Coastal Douglas-fir (Pseudotsuga menziesii var. menziesii (Mirb.) Franco) has generally shown better growth, health and storm stability in older stands compared with other introduced conifers such as Norway spruce (Picea Abies L.) and Sitka spruce (Picea sitchensis Bong Carr.) (Henriksen, 1988). The higher storm stability was also revealed after a severe storm in France in 1982 (DE CHAMPs et al., 1982). However, major drawbacks for a wider use of the species, are a comparably higher sensitivity to frost, poor stem form, especially stem straightness, and a higher risk of damages from browsing and fraying of bark with antlers by roe deer (e.g. Henriksen, 1988). Paradoxically, Coastal Douglasfir seems also to be highly susceptible to windthrow compared to Norway spruce and Sitka spruce in the first years after planting until they become 30 to 40 years (HENRIKSEN, 1988; Jørgensen, 2001). This is likely due to a poor root-shoot ratio, compared with Sitka spruce

\footnotetext{
1) Corresponding author:

Telephone +45 3528 1635, Fax +453528 1517,

E-mail: jkh@kvl.dk
}

and Norway spruce that gradually improves with age (NIELSEN and HANSEN, 1999).

This poor stability stresses the need to investigate the possibility of improving juvenile stability in breeding programs for Coastal Douglas-fir. Genetic variation in the susceptibility to windthrow is found for other coniferious species (e.g. LIEGEL, 1984; TELEWSKI and JAFFE, 1986; WoOlaston et al., 1990; GWAZE et al., 2000; JoHNSTON et al., 2003) and in 6-7-year-old Coastal Douglas-fir (SILEN et al., 1993).

From a breeding point of view, Douglas-fir represents a dilemma when allocating priorities to species. The species is on the one hand sparsely used in Danish forestry mainly due to the problems mentioned above, which point toward low priority compared to more widely planted species. On the other hand, tree improvement may reduce some of the weaknesses of the species, and thereby lead to increased planting of the species in the Danish Forestry. As a compromise, it was decided by the Danish Tree Improvement Station, the managing authority for a majority of Forest Seed Orchards in Denmark, to establish a low cost breeding programme based on a breeding seed orchard (BSO) concept (BARNES, 1995), i.e. a seedling seed orchard (SSO) that combines progeny testing, , and commercial seed production. This approach was chosen in order to avoid establishment of separate progeny trials, and in order to avoid grafting, which is difficult in Douglas fir due to incompatibility.

In this study, we wanted to examine the suitability of the BSO approach for Douglas fir in Denmark by estimating (i) the genetic variation for in particular windthrow susceptibility, but also growth, stem straightness, forking, and bud burst in young Coastal Douglas-fir, (ii) predict the possible gains that we can achieve from multi-trait selections in a seedling seed orchard with Coastal Douglas-fir.

\section{Material and Methods}

A seedling seed orchard (SSO) FP.262 with Coastal Douglas fir was in 1994 established by the Danish State Forest Tree Improvement Station on farm land at the

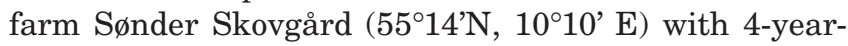
old seedlings based on 97 open pollinated families. These originated from 54 plus-trees selected in five selected stands, and from 43 plus-tree clones represented in four older clonal seed orchards (Table 1). All trees in the five stands, and trees represented as clones in the 
clonal seed orchards (CSO), originate from Danish commercial plantations, mainly classified as approved seed stands.

\section{The origin of the open pollinated families in the SSO}

Plus-trees selected for CSO FP.210 were primarily selected for superior stem straightness and for low frequency of second flushing in their original stands. Plus trees selected for CSO FP.228 and CSO FP.229 were among the dominant trees with the straightest stems. CSO FP.228 consists of 17 clones and CSO FP.229 consists of 15 clones. 13 of the clones are common in the two clonal seed orchards. Thus, the two clonal seed orchards are almost identical and they are located close to each other. Consequently, they were considered as one population. Seed was harvested from different clones in the two clonal seed orchards with one exception.

The CSO FP.232 - located in France - consists of grafts from dominant trees selected for late flushing, stem straightness and for low contrast between early and late wood determined by X-ray densiometry. The trees were selected in a Danish stand, Department 295, Kompedal Plantage $\left(56,15^{\prime} \mathrm{N}, 9,15^{\prime} \mathrm{E}\right)$ originating from Darrington, USA (KJÆR et al., 1996). All trees from one of the families from the CSO FP. 232 were dead when the seedling seed orchard was measured last time in 1999 .

Stem straightness and above average growth was the selection criterion when selecting plus-trees in the five stands F.398, F.488, F.580, F.581 and F. 582.

Three of the populations, the approved stands F.580, F.581 and F.582 are of the same origin. This is also the case for the two clonal seed orchards CSO FP.228, CSO FP. 229 and the approved stand F.488 (Table 1).

None of the clones from the clonal seed orchards had previously been progeny tested, but seedlots from the clonal seed orchards FP 210, FP228 and FP229 has been included in a provenance test in Denmark, where they exhibit superior stem form suggesting that the simple plus tree selection has provided some gain in this trait (KJÆR et al., 1996).

\section{Experimental design}

The seedling seed orchard was established with 22 blocks. Each of the 22 blocks consisted of 99-101 plots made up of three plants in a row from one family. Some unbalance was present, thus some families were not represented in all blocks and some families were represented twice in some of the blocks. Blocks were placed consecutively after each other from west to east and family plots were distributed randomly in the blocks. Each block consisted of approximately three rows. The distance between rows was 3 metres and the distance between trees in the rows 1 metre.

\section{Assessments}

The developmental stage of the lateral bud was scored in spring 1999 using the KRUTZSCH (1973) scale with scores from 0-7, where 7 denotes a fully developed shoot.

In November 1999, a severe westerly storm caused many trees to lean over. The degree of inclination was recorded in the spring 2000 , i.e. 6 years after establishment (10 years old trees) using a score from 0 to 6 for the inclination deviaton from vertical of $0-10^{\circ}$ (score 0 ), $11-20^{\circ}$ (score 1 ), 21-30 (score 2), 31-40 (score 3), $41-50^{\circ}$ (score 4), 51-60 (score 5) and $>60^{\circ}$ (score 6), respectively. A protractor was used to record the inclination. A line with a weight was used to find the vertical line for the protractor. Height and diameter at breast height was also measured, the number of forks were recorded and stem straightness was scored using a scale from 1 to 9 where trees with a perfect straight stem received the score of 9 (Table 2 ).

\section{Statistical analysis}

The following linear mixed model was applied to estimate genetic parameters and breeding values

$$
Y_{i j k l}=\mu+P_{j}+b_{i}+\delta_{i j}+f_{k(j)}+\rho_{i k(j)}+e_{i j k l}
$$

where $Y_{i j k l}$ is the measurement on a single tree $l$ of family $k$ of population $j$ in block $i, \mu$ is the general mean, $P_{j}$ is the fixed effect of population $j, b_{i}$ is the random effect of block $i, \delta_{i j}$ is the random interaction between block $i$

Table 1. - Base populations and number of families within populations represented in the seedling seed orchard.

\begin{tabular}{lcl}
\hline Populations & $\begin{array}{c}\text { Number of OP Origin } \\
\text { families in } \\
\text { SSO }\end{array}$ \\
\hline Clonal seed orchards: & 17 & Ortets selected in nine stands. \\
CSO. FP.210 & 18 & $\begin{array}{l}\text { F.280, Hvidkilde Forest District, which again } \\
\text { possibly origin from stand F.58, Langesø. }\end{array}$ \\
CSO. FP.228/229 & 8 & Kompedal plantage. Origin Darrington, USA. \\
CSO. FP.232 & & \\
Approved seed stands: & 7 & Silkeborg State Forest District \\
F.398 & 22 & F.280, Hvidkilde Forest District. \\
F.488 & 6 & F.41b, Linå Vesterskov. \\
F.580 & 8 & F.41 and F.41b, Linå Vesterskov. \\
F.581 & 11 & F.41 and F41b, Linå Vesterskov. \\
F.582 & &
\end{tabular}

CSO: Clonal seed orchard; SSO: Seedling seed orcchard; F: Approved seed stand. 
Table 2. - Principles for the score of stem straightness.

\begin{tabular}{cll}
$\begin{array}{c}\text { Stem straightness } \\
\text { score }\end{array}$ & & \multicolumn{1}{c}{ Description } \\
\cline { 1 - 1 } $\begin{array}{c}1 \\
2\end{array}$ & & Uncertain leader direction and several very serious leader losses. \\
3 & Uncertain leader direction and several serious leader losses. \\
4 & Curved stems, up to 1-2 leader losses. \\
$5-6$ & In principle almost straight stem, up to 1-2 leader losses. \\
7 & Straight stems that may have weak curves at the base. \\
8 & Straight stems, accepted with small leader losses at the top. \\
9 & Fully straight stems. \\
\hline
\end{tabular}

and populaton $j, f_{k(j)}$ is the random effect of family $k$ within population $j$ with $\operatorname{Var}\left(f_{k(j)}\right)=\sigma^{2}, \rho_{i k(j)}$ is the random effect of plots with $\operatorname{Var}\left(\rho_{i k(j)}\right)=\sigma_{\rho}^{2}$, and $e_{i j k l}$ is the residual error (within plot error) with $\operatorname{Var}\left(e_{i j k l}\right)=\sigma_{e}^{2}$ assumed to have a normal distribution.

The linear mixed model equation in matrix notation was

$$
\mathbf{y}=\mathbf{X b}+\mathbf{Z} \mathbf{u}+\mathbf{e}
$$

where $\mathbf{y}$ is the $\mathrm{n} \mathbf{x} 1$ vector of observations, $\mathbf{X}$ is the $n \times p$ design matrix associating the observations with fixed effects in vector $\mathbf{b}, \mathbf{Z}$ is the $n \times q$ design matrix associating the observations with the random effects in vector $\mathbf{u}$ (block, family- and plot effects) and $\mathbf{e}$ is the $n \times 1$ vector of residual effects. Estimates of fixed and prediction of random effect were obtained solving the mixed model equation (HENDERSON, 1984)

$$
\left[\begin{array}{cc}
\mathbf{X}^{\prime} \mathbf{R}^{-1} \mathbf{X} & \mathbf{X}^{\prime} \mathbf{R}^{-1} \mathbf{Z} \\
\mathbf{Z}^{\prime} \mathbf{R}^{-1} \mathbf{X} & \mathbf{Z}^{\prime} \mathbf{R}^{-1} \mathbf{Z}+\mathbf{G}^{-1}
\end{array}\right]\left[\begin{array}{l}
\widehat{\mathbf{b}} \\
\hat{\mathbf{u}}
\end{array}\right]=\left[\begin{array}{c}
\mathbf{X}^{\prime} \mathbf{R}^{-1} \mathbf{y} \\
\mathbf{Z}^{\prime} \mathbf{R}^{-1} \mathbf{y}
\end{array}\right]
$$

where $\mathbf{R}$ is the variance-covariance matrix of residuals and $\mathbf{G}$ is the direct sum of the variance-covariance matrices of each of the random effects. Residuals are normally considered independent giving $\mathbf{R}=\sigma_{\eta}^{2} \mathbf{I}$ where $\sigma_{\eta}^{2}$ is the independent residual variance and $\mathbf{I}$ is an identity matrix. However, spatial analysis was examined at individual tree level in rows and columns of the SSO (according to GILMOUR et al., 1997; GILmour et al., 1999; DutKowski et al., 2002). Thus, (according to Gilmour et al., 1997; Gilmour et al., 1999; Gilmour et al., 2002; DutKowski et al., 2002), $\mathbf{R}$ was expanded to

$$
\mathbf{R}=\sigma_{\xi}^{2}\left[\operatorname{AR} 1\left(\rho_{\text {col }}\right) \otimes \operatorname{AR} 1\left(\rho_{\text {row }}\right)\right]+\sigma_{\eta}^{2} \mathbf{I}
$$

where $\sigma_{\xi}^{2}$ is the spatial residual variance, $\sigma_{\eta}^{2}$ is the independent residual variance, $\mathbf{I}$ is an identity matrix, and $\operatorname{AR} 1(\rho)$ is a first-order autoregressive correlation matrix for ordered spatial coordinates of size $n$ (rows or columns)

$$
\operatorname{AR} 1(\rho)=\left[\begin{array}{ccccc}
1 & \rho & \rho^{2} & \ldots & \rho^{n} \\
\rho & 1 & \rho & \ldots & \ldots \\
\rho^{2} & \rho & 1 & \ldots & \ldots \\
\ldots & \ldots & \ldots & \ldots & \ldots \\
\rho^{n} & \ldots & \ldots & \ldots & 1
\end{array}\right]
$$

where $\rho$ is the autocorrelation parameter (GILMOUR et al., 1999; Gilomour et al., 2002; DuTKOWsKI et al., 2002).

Only significant $(\mathrm{P}<0.05)$ autoregressive correlation parameters were used. The significance of a parameter was tested using a one-tailed likelihood ratio test (GILMOUR et al., 1999); for model A with the parameter included and sub-model $\mathrm{B}$ without the parameter included. The test statistic computed was

$$
\left.G_{A \rightarrow B}=2\left[\log L_{B}\right)-\log L_{A}\right]
$$

where $\log L_{B}$ is the $\log$ likelihood value for the submodel $\mathrm{B}$ and $\log L_{A}$ is the $\log$ likelihood value for the model A and where $G_{A \rightarrow B}$ follows a $\chi^{2}{ }_{1}$ - distribution (GILmour et al., 1999). Additionally, the criterion AIC of Akaike was used to select between models (AKAIKE, 1973; WADA and KASHIWAGI, 1990).

$$
A I C=-\log L+2 p
$$

where $\log L$ is the $\log$ likelihood and $p$ the number of independent fitted parameters included in the model and where the model with lowest value was chosen.

Breeding values across populations were estimated by adding the predicted population deviation from the overall mean (WHITE and HoDGE, 1989). The estimation of genetic parameters, prediction of breeding values, examination of heteroscadicity and distribution of residuals was made in the software program ASReml (GILMOUR et al., 1999; Costa E Silva et al., 2001; DutKowski et al., 2002; GiLmour et al., 2002).

Phenotypic correlation coefficients between traits $x$ and $y$ were estimated as

$$
\bar{r}_{p}=\left(\hat{\sigma}_{f x y}+\hat{\sigma}_{\rho x y}+\hat{\sigma}_{e x y}\right) / \sqrt{\hat{\sigma}_{f x y}^{2}+\hat{\sigma}_{\rho x y}^{2}+\hat{\sigma}_{e x y}^{2}}
$$

where $\hat{\sigma}_{f x y}$ is the estimated family covariance between trait $x$ and $y, \hat{\sigma}_{\rho x y}$ is the estimated plot covariance between trait $x$ and $y$, and $\hat{\sigma}_{e x y}$ is the estimated within plot covariance between trait $x$ and $y$. Genetic additive correlation coefficients between trait $x$ and $y$ were estimated as:

$$
\hat{r}_{a}=\sigma_{f x y} / \sqrt{\sigma_{f x}^{2} \sigma_{f y}^{2}}
$$

(e.g. BECKER, 1984; FALCONER, 1989). The individual tree narrow-sense heritability in the SSO was estimated as

$$
\hat{h}_{n s}^{2}=4 \sigma_{f}^{2} /\left(\sigma_{f}^{2}+\sigma_{p}^{2}+\sigma_{e}^{2}\right)
$$

where $\hat{\sigma}_{f}^{2}$ is the estimated family variance, $\hat{\sigma}_{\rho}^{2}$ is the estimated plot error variance and $\hat{\sigma}_{e}^{2}$ is the residual variance. Thus, we considered the open pollinated families as half-sib families (FALCONER, 1989), i.e. the narrow-sense heritability estimates are possibly exaggerated since some of the trees in the families possibly are 
full sibs (CAMPBELL, 1979; CAMPBELL, 1986). Standard errors for the genetic parameters were estimated from Taylor series approximations (GILMOUR et al., 1999).

\section{Prediction of genetic gains and genetic diversity as consequence of a thinning in the SSO}

Based on the predicted breeding values for the trees in the seedling seed orchard, it was possible to predict the genetic gains assuming first a selection of one of the three trees in each plot (i.e. two of three trees in each plot were assumed removed), and then making selections among the remaining trees in the seedling seed orchard. Multi-trait selection among these trees was based on index values calculated by multiplying the predicted breeding values of the trees for the different traits with certain weights. Different multi-trait scenarios were examined with three sets of weights for the traits (Table 5). The number of individuals selected from each family was restricted to obtain different status number, but the restriction was less for families with trees of high breeding or index values to obtain higher genetic gains at the same genetic diversity (as found by LINDGREN and MATHESON, 1986; LINDGREN et al., 1989; RODRIGUEZ, 2000).

The following exponential function (SIT and PoulinCostello, 1994) was found sufficient variable (by varying the parameters in the function) to vary the maximum number of trees selected from each family $i=$ $1,2 \ldots .96$ where family $i=1$ is the family with the highest average breeding value and family $i=96$ is the family with the lowest average breeding value.

$$
\left.\max _{i}=\operatorname{Integer}\left(\left(e^{\mathrm{a}-\mathrm{bi}}\right)+c\right)\right)
$$

where $\max _{i}$ is the maximum number of trees that can be selected from family $i$, and $\mathrm{a}, \mathrm{b}$, and $\mathrm{c}$ are parameters. Trees with the best breeding values among these remaining trees were then selected. The average coancestry and status number (LINDGREN et al., 1996; LINDGREN et al., 1997) was estimated for these final selected trees using the relationship matrix. The relationship matrix was estimated by use of the procedure INBREED in SAS ${ }^{\circledR}$ (SAS Inst. Inc, 1999). The relationship coefficient is twice the coancestry (FALCONER, 1989). Thus, by summing up the coancestry coefficients (half the relationship coefficients) and dividing by the number of crosses between the trees it was possible to obtain the average coancestry assuming random mating. The status number was then estimated according to LINDGREN et al. (1996) and LINDGREN et al. (1997) as

$$
N_{s}=\frac{1}{2 \Theta}
$$

where $N_{s}$ is the status number and $\Theta$ is the average coancestry. A variety of selection scenarios were examined with different parameter values for the different sets of weights. Thus, for different sets of weights on the traits, combinations of parameters (a, b, c in function 6 ) were found to maximise the average index value at different levels of relatedness expressed by the status number $N_{s}$.

Tree to tree variation in flowering and seed production has proved highly variable in a Coastal Douglas fir clon- al seed orchard in Denmark and might reduce the expected effective size by $50 \%$ (KJÆR and WELLENDORF, 1998; HANSEN, 1999). Thus, we estimated a possibly more realistic effective population size from the status number $N_{e}=0.5 N_{s}$.

The number of potential crosses between half sibs was estimated from the average coancestry as

$$
\left(0.5 N+0.125 N_{S C}\right) / N^{2}=\Theta \Leftrightarrow\left(\Theta N^{2}-0.5 N\right) / 0.125=N_{S C}
$$

where $N$ is the number of selected trees, $N_{S C}$ is number of potential crosses between sibs (all assumed to half sibs in this case) and $\Theta$ is the average coancestry. From the number of potential crosses between half sibs it was possible to estimate an average coancestry assuming that half of the sibs actually are full sibs using equation 8 , i.e.

$$
\left(0.5 N+\left(0.125 N_{H S C}+0.250 N_{F S C}\right) / N^{2}=\Theta\right.
$$

where $N_{H S C}$ is the number of crosses between half sibs and $N_{F S C}$ is the number of crosses between full sibs and where $N_{H S C}=0.5 N_{S C}$ and $N_{F S C}=0.5 N_{S C}$.

A possible influence of inbreeding on the results for height growth was investigated by reducing the predicted gains for height from potential selfings and crosses between half sibs, while considering that a large proportion of seedlings from these crosses are purged already at the nursery (Woods et al., 2002; WANG et al., 2004). Thus, it was assumed that the height in offspring from mating between half-sibs was reduced by $12.6 \%$ of the mean height and that the height in offspring from selffertilisations was reduced by $47 \%$ of the mean height according to figures in table 2 in WANG et al. (2004). According to figures from WooDs et al. (2002), it was assumed that the probability of producing acceptable seedlings was $3 \%$ and $55 \%$ from self-fertilisations and mating between half sibs, respectively.

To obtain an indication of the importance of reducing the average inclinations score, we estimated the regression between the mean inclination score of a population and the mean percentage of trees with no inclination of the population in the seedling seed orchard. Thus, the percentage of trees with an inclination score of 1 to 6 was estimated for each population within each block, as well as the mean inclination score for each provenance in each block. Afterwards least square means were estimated for the populations from the following mixed model

$$
Y_{i j}=\mu+P_{j}+b_{i}+e_{i j}
$$

where $Y_{i j}$ is mean inclination score of population $j$ in block $i$, or the percentage of trees with an inclination score above 0 of population $j$ in block $i, \mu$ is the general mean, $b_{i}$ is the random effect of block $i, P_{j}$ is the fixed effect of population $j$, and $e_{i j}$ is the residual error. A linear regression between percentage of trees with an inclination score above 0 for a population and the inclination score for the population proved highly significant with a regression coefficient of $55 \%(\mathrm{P}<0.0001)$ per unit score $\left(\mathrm{R}^{2}\right.$ of 0.95$)$, i.e. a reduction of the inclination score with one unit corresponded to a reduction of the percentage of trees with an inclination score of 1 to 6 by $55 \%$. 


\section{Results}

At age 10 years, the mean height and diameter at breast height was 3.5 metres and $4.2 \mathrm{~cm}$, respectively. The mean stem straightness score was 5.4. The mean number of forks was 1 . The mean inclination score was 0.78 . Mean bud burst score was 2.8. Inclination scores above 2 were seldom (Fig. 1). The frequency of trees with an inclination was $60 \%$, mainly distributed to the score 1 and 2 (Fig. 1). The frequency of trees with forks was $74 \%$. In comparison with other studies dealing with Coastal Douglas fir of approximately same age this seems high. In a 9-year-old progeny test SCHERMANN et al. (1997) found a frequency of trees with at least one fork or ramicorn of $26 \%$ and $46 \%$, respectively. The total proportion of trees in a progeny tests series at three sites with forks, or forks and ramicorns, was $7.5 \%$ at age 12 in a study by TEMEL and ADAMs (2000).

The narrow sense heritability estimate was $h^{2}=0.40$ for both height and diameter when considering the families as half-sib families (Table 3). Both traits showed significant autocorrelation in the row and column direction (Table 3). The narrow sense heritability estimate was $h^{2}=0.17$ and $h^{2}=0.20$ for inclination score and number of forks, respectively. There was significant autocorrelation in the column direction for the inclina-

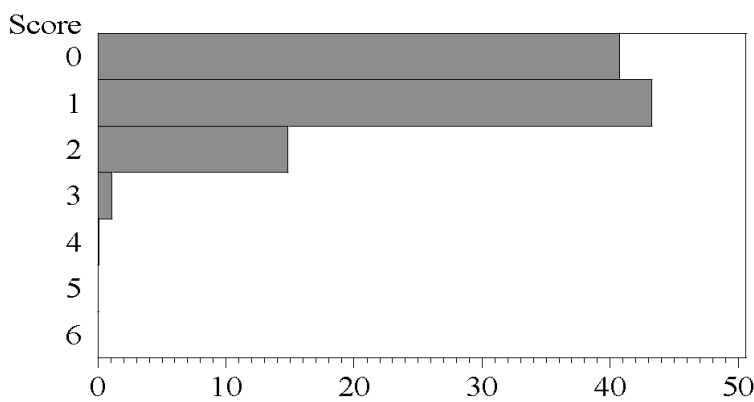

Figure 1. - Distribution of inclination scores in 1999. tion score and in the row and column direction for number of forks (Table 3). Stem straightness score showed a narrow sense heritability of $h^{2}=0.48$ and significant autocorrelation in both the row and column direction. The narrow sense heritability estimate for bud burst score was $h^{2}=0.63$.

Height and diameter was highly correlated with an additive genetic correlation of $r_{g}=0.93$ (Table 4). Otherwise, genetic correlation coefficients were low to moderate. The additive genetic correlation of stem straightness with height and diameter was $r_{g}=-0.17$ and $r_{g}=-0.30$, respectively. Thus, fast growing families had a tendency to have fewer trees with straight stems. The additive genetic correlation was $r_{g}=-0.30$ between number of forks and inclination score; indicating that families with an inclination avoided leader breaks. Families with high bud burst scores, i.e. early bud burst tended towards a comparable lower height as indicated by the additive genetic correlation of $r_{g}=-0.22$ between burst of buds and height. The genetic correlation between stem straightness and inclination score was $r_{g}=-0.34$, i.e. trees with high stem straightness scores had lower inclinations (Table 4). This could indicate an earlier influence of a poor stability on the stem straightness.

\section{Predicted genetic gains}

The genetic gain in inclination score by removing 2 of 3 trees with the worst inclination in each plot in the seedling seed orchard was predicted to $R=-0.08$ (not shown). This corresponded to a $4 \%$ decrease of the frequency of trees with an inclination above $10^{\circ}$ in a population. The status number was 246 among the selected 2017 half sibs (not shown).

Predicted gain in inclination score from selections within family plots followed by selection among the remaining 2017 half sibs, i.e. a combined within and between family selection, varied between $R=-0.18$ and

Table 3. - Variance components and individual narrow sense heritability for height, diameter at breast height, stem straightness, bud burst, inclination score and number of forks. Non-significant parameters are excluded (n.s.).

\begin{tabular}{|c|c|c|c|c|c|c|}
\hline & Height & $\begin{array}{l}\text { Dia- } \\
\text { meter }\end{array}$ & $\begin{array}{c}\text { Stem } \\
\text { straight- } \\
\text { ness }\end{array}$ & Bud burst & $\begin{array}{l}\text { Inclina- } \\
\text { tion }\end{array}$ & N-forks \\
\hline Unit & $\mathrm{dm}$ & $\mathrm{mm}$ & score $1-9$ & score $1-9$ & score $0-6$ & \\
\hline Mean & 35 & 42 & 5.41 & 2.8 & 0.78 & 1.00 \\
\hline \multicolumn{7}{|l|}{ Source of variation } \\
\hline Provanance $\mathrm{x}$ replication interaction & n.s. & n.s. & n.s. & n.s. & n.s. & n.s. \\
\hline Replication & n.s. & n.s. & n.s. & 0.042 & n.s & n.s. \\
\hline Family within population & 3.2 & 12 & 0.072 & 0.060 & 0.023 & 0.040 \\
\hline Plot variance & 1.8 & 2 & 0.019 & 0.033 & n.s. & 0.030 \\
\hline Residual & 26.9 & 101 & 0.512 & 0.289 & 0.532 & 0.716 \\
\hline Phenotypic variance & 31.9 & 114.3 & 0.603 & 0.381 & 0.555 & 0.786 \\
\hline Phenotypic standard deviation & 5.6 & 10.7 & 0.78 & 0.617 & 0.745 & 0.887 \\
\hline $\mathrm{CV} \% \#$ & 16 & 26 & & & & \\
\hline $\mathrm{h}_{\mathrm{ns}}^{2}$ & 0.40 & 0.40 & 0.48 & 0.63 & 0.17 & 0.20 \\
\hline $\operatorname{StdErr}\left(h_{n S}^{2}\right)$ & 0.07 & 0.07 & 0.11 & 0.09 & 0.04 & 0.04 \\
\hline Autocorrelation parameter rows & 0.94 & 0.95 & 0.97 & n.s. & n.s. & 0.88 \\
\hline Autocorrelation parameter columns & 0.95 & 0.95 & 0.94 & n.s. & 0.97 & 0.96 \\
\hline
\end{tabular}

\# Coefficient of variation (\%): $100 \mathrm{x}$ phenotypic standard deviation divided by the mean. 
Table 4. - Phenotypic $\left(r_{p}\right)$ and genetic $\left(r_{a}\right)$ correlation coefficients with standard errors (italic)

\begin{tabular}{|c|c|c|c|c|c|}
\hline Trait & Trait & $r_{p}$ & & $r_{a}$ & \\
\hline \multirow[t]{5}{*}{ Height } & Diameter & 0.84 & 0.00 & 0.93 & 0.02 \\
\hline & Inclination & -0.04 & 0.02 & 0.05 & 0.16 \\
\hline & Number of forks & 0.08 & 0.02 & -0.09 & 0.15 \\
\hline & Stem straightness & -0.15 & 0.02 & -0.17 & 0.14 \\
\hline & Bud burst & -0.06 & 0.02 & -0.22 & 0.13 \\
\hline \multirow[t]{4}{*}{ Diameter } & Inclination & 0.07 & 0.02 & 0.13 & 0.15 \\
\hline & Number of forks & 0.02 & 0.02 & -0.12 & 0.15 \\
\hline & Stem straightness & -0.29 & 0.02 & -0.30 & 0.13 \\
\hline & Bud burst & -0.06 & 0.02 & -0.22 & 0.13 \\
\hline \multirow[t]{3}{*}{ Inclination } & Number of forks & -0.14 & 0.02 & -0.30 & 0.15 \\
\hline & Stem straightness & -0.31 & 0.01 & -0.34 & 0.13 \\
\hline & Bud burst & 0.05 & 0.02 & 0.22 & 0.14 \\
\hline \multirow[t]{2}{*}{ Number of forks } & Stem straightness & 0.06 & 0.02 & 0.00 & 0.00 \\
\hline & Bud burst & -0.03 & 0.02 & 0.00 & 0.00 \\
\hline Stem straightness & Bud burst & 0.00 & 0.02 & 0.17 & 0.64 \\
\hline
\end{tabular}

Table 5. - Results from different selection scenarios with combined between family and within family selections and with different weights for different traits - height (H), diameter at breast height (DBH), stem straightness (STR), inclination (INCL), change in $\%$ trees with inclination (INCL\%), number of forks (FORK) and bud burst (BUD). Selection scenario A1-A3 has only a weight on inclination, B1-B6 have a second, and C1-C6 a third set of economic weights. To prevent frost damages due to early bud burst, this trait was given a negative weight. The parameters a, b, c refer to the function [6], i.e. the function determining the maximum number of individuals selected in each family, depending on the average breeding value of the family.

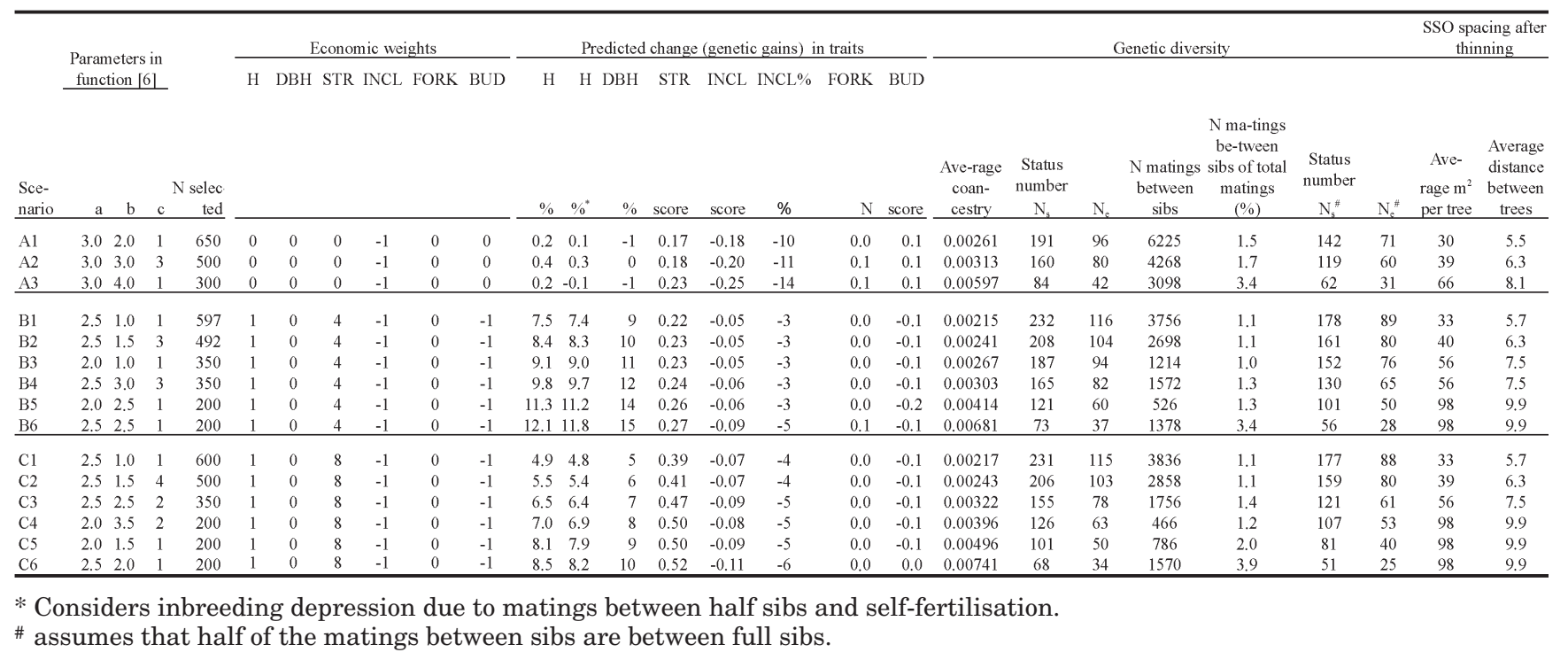

$R=-0.25$ depending on the number of selected trees and the restrictions on the average coancestry in the seedling seed orchard (Table 5, scenarios A1-A3). A selection of more individual trees in families with good overall performance concerning the index value was superior compared to a selection with equal selection in each family as expected from Rodriguez (2000), (Fig. 2).

More balanced selection scenarios were examined, aiming to increase growth and improve stem straightness as well. Again, the first approach was to make within plot selections based on index values (selection of one of three trees), followed by combined between family and within family selections. In these scenarios the genetic gains in height varied between 5 and 12 percentage, genetic gains in stem straightness score varied between $R=0.22$ to 0.52 , while the wind susceptibility score was reduced by $R=0.05$ to 0.11 depending on selection intensity, weights for the traits and restrictions on the number of trees selected from families with the best average index values (Table 5, fig. 3 , scenarios $\mathrm{B} 1-\mathrm{B} 6$ and $\mathrm{C} 1-\mathrm{C} 6$ ).

The predicted gains in height were only slightly reduced when considering the influence of inbreeding, reflecting that the proportion of crosses between halfsibs was below 4\% in all scenarios B1-B6 and C1-C6 (Table 5). 
Hansen et.al. Silvae Genetica (2005) 54-4/5, 218-227

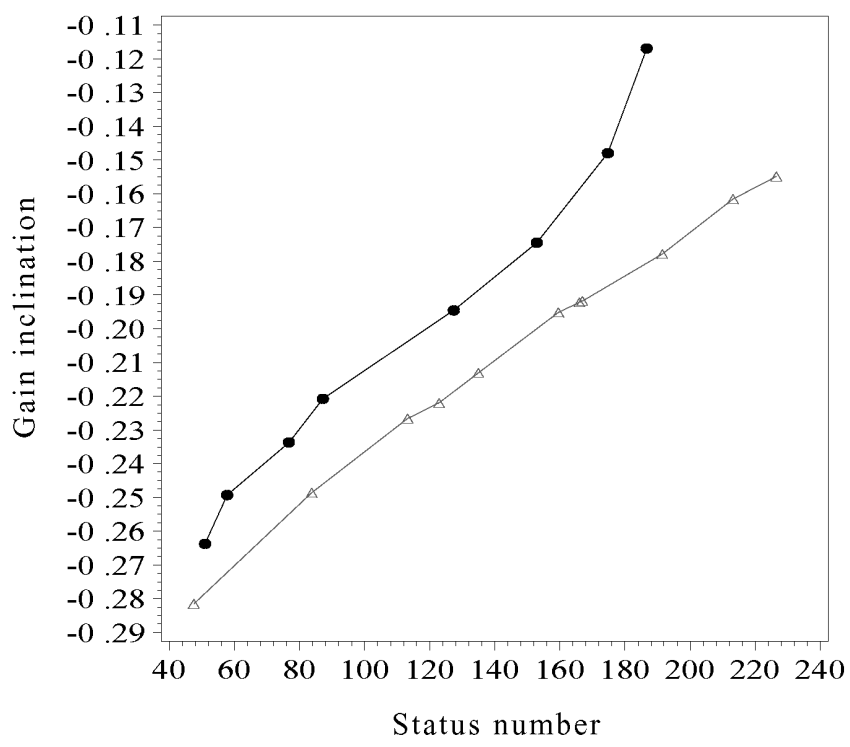

Figure 2. - Comparison of predicted genetic gains (reduction of inclination) selecting the same number of trees from each amiby (dots), or selecting more individual trees from the best performing families (triangle). Notice that a large negative value in the gain, ie. a reduction in the score, is preferable.
Discussion

In this study, the opportunity to reduce windthrow susceptibility in Coastal Douglas-fir was low and the missing effect of height on the inclination in the seedling seed orchard was a surprise, but is possibly explained by a comparative low frequency of severe inclinations (Fig. 1). A genetic variation in the susceptibility to windthrow in Coastal Douglas-fir was also found in a 6-year-old and a 7-year-old genetic field test with families from controlled crosses of 9 and 13 parants, respectively. The mean height was 1.6 and 2.1 metres in the two tests, respectively (SILEN et al., 1993). General combining ability (GCA) and specific combining ability (SCA) accounted for $18.6 \%$ and $22.5 \%$ of the total variance for susceptibility in the two genetic field tests, respectively - after adjustments due to height, and the variation from SCA was near equal to GCA (SILEN et al., 1993). Height as covariant proved significant and explained approximately a third of the variation in surceptibility. Therefore, only seven out of 138 crosses in the two sets exceeded $10 \%$ superiority in both mean height and windthrow susceptibility (SILEN et al., 1993). As noticed by SILEN et al. (1993), it seems difficult to
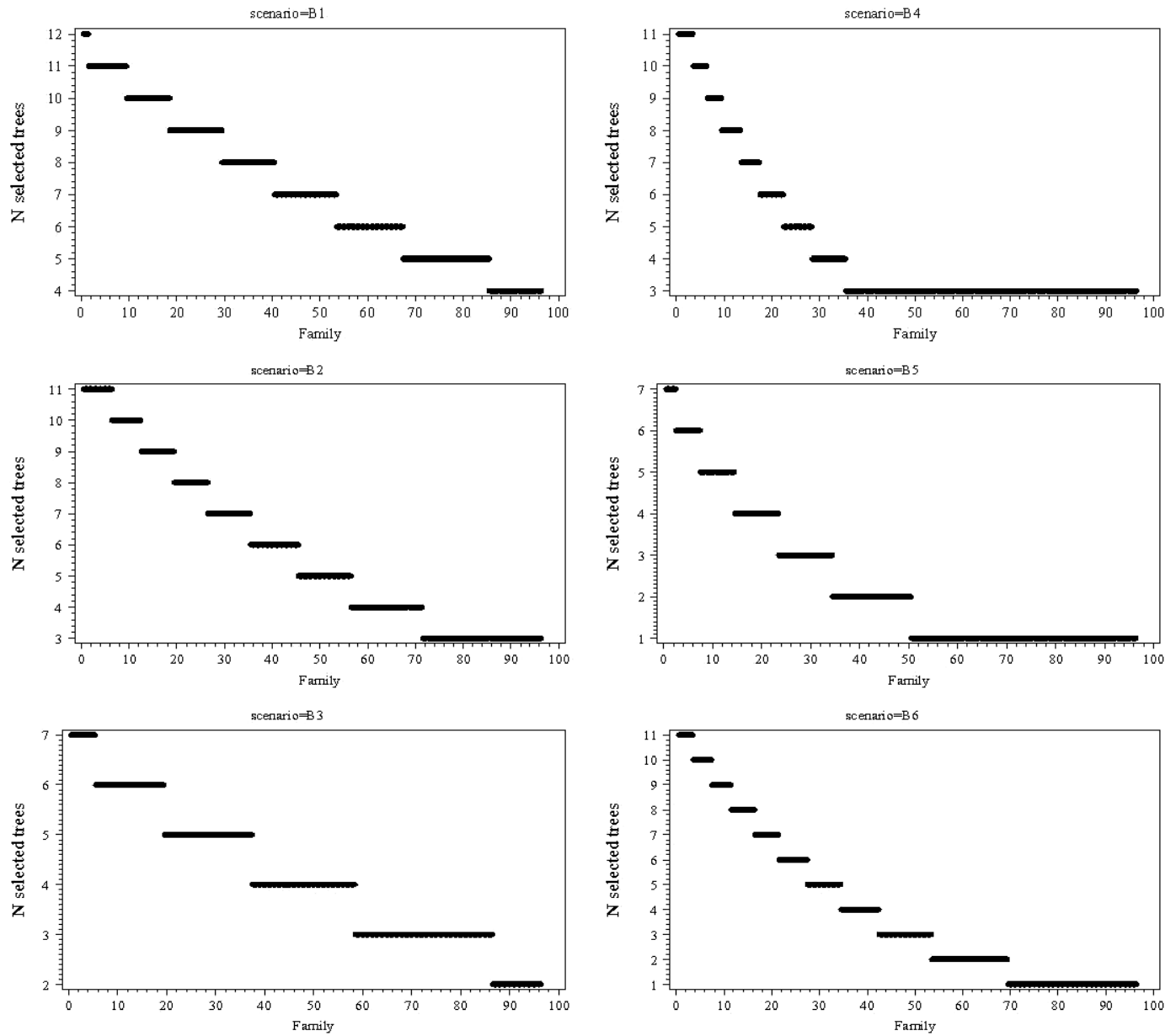

Figure 3. - Maximum number of trees allowed selected from the families 1-96 in the selection scenarios B1-B6 determined by the parameters in function [6], see table 5. The families are sorted according to their average index value, ie. family 1 is characterised by the best average index value and family 96 by the poorest average index value. The final number of selected trees are the same in scenario B3-B4 (see table 5), but the gains are slightly higher in scenario B4 compared with B3, since families with the highest average index value were allowed to contribute with more trees. The situation is similar for seemario B5 versus B6.

224

DOI:10.1515/sg-2005-0032

edited by Thünen Institute of Forest Genetics 
include wind susceptibility in breeding programs if these rely on natural, and thus occasional and random events. Nevertheless, the significant genetic variation encourages further investigations on the genetic variation of stability in young Coastal Douglas-fir trees.

This study showed a favourable, though moderate additive genetic correlation between late bud burst and height as found in previous studies (e.g. BIROT and Christophe, 1983; Li and AdAms, 1993; Stevenson et al., 1999). The importance of late bud burst is stressed by a high genetic correlation with spring frost susceptibility (O’NeILL et al., 2000). Unfortunately, late bud burst is moderately genetically correlated with autumn frost susceptibility (STEVENSON et al., 1999; O'NEILL et al., 2000) making it necessary to include early autumn frost susceptibility in the breeding programs of Coastal Douglas-fir.

Weak to moderate individual tree and family heritability estimates for stem sinuosity was also found in other investigations of young Coastal Douglas-fir (BIROT and Christophe, 1983; AdAMs and BASTIEN, 1994; SCHERMANN et al., 1997; TEMEL and ADAMS, 2000; VARGAS-HERNANDEZ et al., 2003). The indication of a weak unfavourable genetic correlation between stem straightness and growth in this study corresponds to the findings concerning growth and stem sinuosity in other investigations with material of corresponding age (BIROT and Christophe, 1983; Schermann et al., 1997; Temel and ADAMS, 2000; VARGAS-HERNANDEZ et al., 2003). In material of age 9-12 years there was a connection between stem sinuosity and the development of forks and ramicorns in contrast to this study, whereas there was only a weak to moderate genetic correlation between second flushing frequency and stem sinuosity (ADAMS and BASTIEN, 1994; SchERMANn et al., 1997). Second flushing frequency is positively correlated with growth in the first 10 years (ADAMS and BASTIEN, 1994; SCHERMANN et al., 1997). The negative correlation between stem straightness and inclination score is favourable, but the finding needs verification from other studies.

TEMEL and ADAMs (2000) found a genetic correlation of 0.36 between stem sinuosity at age 12 and stem sinuosity at the outer bole in the lowest 5 metres from the ground after 24 years. In another study with Coastal Douglas-fir, 11-15\% of the log volume was affected by grain defects because of stem sinuosity in logs from trees with an average diameter at breast height of 23.9 to $26.2 \mathrm{~cm}$ (SPICER et al., 2000). These results suggest at first sight that the importance of reducing early stem sinuosity is small. However, inner boards cut from logs with a sinuous centre are downgraded.

In the seedling seed orchard only $6 \%$ of the trees scored 7 and 8 in stem straightness and none scored 9 . Therefore, it seems reasonable to improve stem straightness at least moderately at age 10 years to obtain sufficient trees with satisfactory stem straightness at the time where the most valuable timber production starts.

A moderate family heritability concerning forking has also been found in previous investigations (ADAMS and BASTIEN, 1994; SCHERMANN et al., 1997), or steep angled branches-ramicorns (TEMEL and ADAMS, 2000; VARGASHERNANDEZ, 2003). However, a positive and unfavourable genetic correlation with growth was not seen in this study. This contrasts findings in other studies of Coastal Douglas-fir showing a moderate positive genetic correlation between growth and frequency of forking/ramicorns, but the height and diameter at ages from 9-13 were also twice as large as observed in this study (ADAMS and BASTIEN, 1994; SCHERMANN et al., 1997; TEMEL and AdAMs, 2000; VARGAS-HERnANDEZ, 2003).

The heritability estimates for height and diameter were high, compared with heritability estimates from other field trials with Coastal Douglas-fir (e.g. JOHNSON et al., 1997). This reflects possibly that the seedling seed orchard is established on farmland with small climatic variations and heterogeneity in soil fertility. Some concern might rise if the selections based on a farm-field trial are reliable for forest conditions, but Woons et al. (1995) found in a study of Coastal Douglas-fir that farm field test breeding values correlated well with field test breeding values.

The evaluation of the seedling seed orchard suggest that it is possible to obtain significant gains in growth, stem straightness and to some extent reduce wind susceptibility, while retaining an effective population size above 50. Thus, the establishment of the seedling seed orchard was favourable with respect to genetic gains and retaining diversity.

Predicted gains in the SSO are possibly overestimated since the offspring of the plus trees are considered to be half sibs and since future realised gains from the selections naturally depend on genotype-environmental interactions and age-age correlations (FALCONER, 1989). Different flowering and seed production of the trees will also reduce the genetic diversity (e.g. KANG et al., 2003a; KANG et al., 2003b), and emphasise the importance of delaying the final selections in the seedling seed orchard as long as possible, to have the chance to include flowering and seed production in the selections. Selections in the seedling orchard are targeting the specific environment of the seedling seed orchard stressing the need for several seedling seed orchards in case genotype-environment interactions are high for the traits of interest.

The risk that inbreeding depressions will decrease the predicted gains from the seedling seed orchard is substantially low, due to small proportions of crosses between related trees. In particular, when it is considered that trees showing inbreeding depressions are purged from the forest populations and thus will contribute little to the final revenue from a stand (WANG et al., 2004). Thus, WANG et al. (2004) simulated that the final yield of marketable timber at age 90 was decreased by $100 \times\left(0.120 P_{F=0.125}+0.200 P_{F=0.25}\right) \%$ where $P_{F=0.125}$ and $P_{F=0.25}$ was the proportion of seedlings with inbreeding coefficients of 0.125 and 0.25 , i.e. with proportions of half sib, or even full sib crosses, of less than $4 \%$ in this study, the effect of inbreeding depression seems small. The effect of inbreeding will probably be even smaller for stem form, because this trait is less fitness related and therefore likely to be less subject to inbreeding depression. 
The predicted gains from the seedling seed orchard were not compared with genetic gains from a selection in a hypothetical clonal seed orchard with grafted parent plus trees. Thus, it was not possible to estimate comparable genetic gains from such a seed orchard and the SSO that account for the genetic gains from the plus tree selections in the original populations/stands. Only half of these genetic gains are transferred to the offspring in the seedling seed orchard, while genetic gains from the plus tree selections in the original populations are fully retained in the parent trees. This means that the gains from the original plus tree selections are fully reachable in a clonal seed orchard. The possibility that the gains from the plus tree selections outweigh the differences depends naturally on the selection intensity, narrow sense heritability and the phenotypic variance when selecting the plus trees (e.g. RUOTSALAINEN and LINDGREN, 1998; BURDON and KUMAR, 2004). It also depends on the degree of genotype-environment interaction between the sites where the plus trees are standing and the site with the SSO. An advantage using the clonal seed orchard approach is that the plus tree selections are based on mature trees making it more certain that gains are achieved and not reduced significantly due to a poor genetic age-age correlation.

BURDON and KUMAR (2004) did not find the approach of selecting among half sib offspring in progeny tests for the formation of a production population superior to the selection in clonal seed orchards with progeny tested plus trees unless the heritability was above 0.60 . RouTSALAINEN and LINDGREN (1998) compared backward and forward selections for a range of different selection intensities and found also that a forward selection approach was mainly superior to a backward selection approach for a narrow sense heritability $>0.50$ and when plus tree selection intensities were low and/or when the number of offspring in the families was high (100 and mostly 500). Forward selections were contrary to this in general favourable if it was assumed that the whole genetic gain from the plus tree selection was transferred to the progeny, assuming that the progeny was made by pollinating the plus trees with a pollen mix from the selected plus trees (RoUTSALAINEN and LINDGREN, 1998).

So far, we have mainly discussed the results in the context of seed production from improved material, but the SSO approach in Coastal Douglas fir in Denmark is also an attempt to combine seed production from improved material while the SSO along with other seedling seed orchards, also serves as a breeding population for the next generation in the breeding program. This, along with an expected wide use of natural regeneration in Denmark in plantations of Coastal Douglas fir, stresses the need for maintaining a reasonably high genetic diversity in the SSO. This study showed good opportunities to combine genetic gains while at the same time retaining a genetic diversity - corresponding to a status number above 50 .

\section{Acknowledgement}

We wish to thank the Danish State Forest Tree Improvement Station and Forest Engineer JENS ERIK GALBY who collected part of the data for this study.

\section{References}

Adams, W. T. and J. C. Bastien (1994): Genetics of Second Flushing in a French Plantation of Coastal Douglas-fir. Silvae Genet. 43: 345-352.

AKAIKE, H. (1973): Information theory and an extension of the maximum likelihood principle. $2^{\text {nd }}$ Int. Symp. Information Theory, pp. 267-281 in Proc. $2^{\text {nd }}$ International Symposium of Information Theory, edited by B. N. Petrov and F. CsAKI, Akadamiai Kiado, Budapest, Hungary.

BARNES, R. D. (1995): The breeding seedling orchard in the multiple population breeding strategy. Silvae Genet. 44: 81-88.

BECKER, W. A. (1984): Manual of quantitative genetics. 4. Ed. Academic Enterprises Pullman, Washington, U.S.A. $190 \mathrm{pp}$.

Birot, Y. and C. Christophe (1983): Genetic structures and expected genetic gains from multitrait selection in wild populations of Douglas-fir and Sitka spruce. I. Genetic variation between and within populations. Silvae Genet. 32: 141-151.

BuRdon, R. D. and S. KumAR (2004): Forwards versus backwards selection: trade-offs between expected genetic gain and risk avoidance. N. Z. J. For. Sci. 34: 3-21.

CAMPBell, R. K. (1979): Genecology of Douglas-fir in a watershed in the Oregon Cascades. Ecology 60: 1030-1050.

CAMPBELl, R. K. (1986): Mapped genetic variation of Douglas-fir to guide seed transfer in southwest Oregon. Silvae Genet. 35: 85-96.

Costa e Silva, J., G. W. Dutkowski and A. R. Gilmour (2001): Analysis of early tree height in forest genetic trials is enhanced by including a spatial correlated residual. Can. J. For. Res. 31: 1887-1893.

De Champs, J., J. L. Ferron, D. Michaud and N. Savatier (1982): Lecons a tirer de la tempete des 6-8 novembre 1982, Ann. Rech. Sylv. AFOCEL, France: 4-101.

Dutkowski, G. W., J. Costa E Silva, A. R. Gilmour and G. A. Lopez (2002): Spatial analysis methods for forest genetic trials. Can. J. For. Res. 32: 2201-2214.

FALCONER, D. S. (1989): Introduction to quantitative genetics, third ed., Longman Scientific and Technical, UK, $438 \mathrm{pp}$.

Gilmour, A. R., B. R. Cullis and A. P. Verbyla (1997): Accounting for natural and extranous variation in the analysis of field experiments. J. Agric. Biol. Environmen. Stat. 2: 269-293.

Gilmour, A. R., B. R. Cullis, S. J. Welham and R. ThompSON (1999): ASReml Reference Manual. Agicultural Biometric Bulletin No. 3, Orange Australia.

Gilmour, A. R., B. J. Gogel, B. R. Cullis, S. J. Welham and R. Thompson (2002): ASReml User Guide Release 1.0 VSN International Ltd., Hemel Hempstead, HP11ES, UK. 267 pp.

Gwaze, D. P., H. S. Dungey, M. J. Dieters, P. G. Toon and D. G. NiKLES (2000): Interspecific pine hybrids. I. Genetic parameter estimates in Australia. Forest Genetics 7: 11-20.

HANSEN, T. (1999): Impact of flowering phenology on the effective population number in a Douglas Fir (Pseudotsuga menziesii) clonal seed orchard. Manuscript in HANSEN, T.: Impact of flowering phenology on the estimation of effective population numbers. MSc Thesis. 81 pp, The Royal Vet. and Agric University, Copenhagen.

HENDERSON, C. R. (1984): Applications of linear models in animal breeding. University of Guelph, Canada, 462 pp. 
HenRIKsen, H. A. (1988): Skoven og dens dyrkning, Dansk Skovforening, København, 664 pp.

Johnson, G. R., R. A. Sniezko and N. L. Mandel (1997): Age Trends in Douglas-fir Genetic Parameters and Implications for Optimum Selection Age. Silvae Genet. 46: 349-358.

Johnston, A. J., M. J. Dieters, H. S. Dungey and H. M. WALlaCe (2003): Intraspecific hybridization in Pinus caribaea var. hondurensis I. Performance for growth and form traits. Euphytica 129: 147-157.

JøRGENSEN, B. B. (2001): Erfaringer om stormfasthed fra FSL's langsigtede bevoksningsfors $\emptyset$ g. Dansk Skovforenings Tidsskrift 86: 145-208.

KANG, K. S., Y. A. El-Kassaby, W. Y. ChOI, S. U. HAN and C. S. KIM (2003a): Genetic gain and diversity caused by genetic thinning in a clonal seed orchard of Pinus densiflora. Silvae Genet. 52: 220-223.

KANG, K. S., E. D. KJÆR and D. LindGREN (2003b): Balancing genetic diversity and nut production in Corylus avellana collections. Scand. J. For. Res. 18: 118-126.

KJÆR, E. D., H. BARNeR and A. M. D. ANDERSEN (1996): Undersøgelse af afkom fra tre danske douglasgranfrøplantager. Dansk Skovforenings Tidsskrift 81: 1-17.

KJÆR, E. D. and H. WELLENDORF (1998): Studies on the effect of unequal flowering on the effective population number in Danish seed orchard crops. In: Proceedings from the meeting of the Nordic Group for the Management of Genetic Resources of Trees "The biotic and abiotic components of forest tree improvement and gene resource management", held at Høsterkøb, Denmark. Forest Tree Improvement 26: 56-64. The Royal Vet. and Agric University, Copenhagen.

KRUTZSCH, P. (1973): Norway spruce development of buds Internal report. International Union of Forest Research Organizations, Vienna, IUFRO S2.02.11.

LI, P. and W. T. ADAMS (1993): Genetic control of bud phenology in pole-size trees and seedlings of coastal Douglas-fir. Can. J. For. Res. 23: 1043-1051.

LiEGEL L. H. (1984): Results of 5- to 6-yr-old provenance trials of Pinus oocarpa Schiede on eight sites in Puerto Rico. Silvae Genet. 33: 223-230.

LindGren, D. and A. C. MAtheson (1986): An algorithm for increasing the genetic quality of seed from seed orchards by using the better clones in higher proportions. Silvae Genet. 35: 173-177.

LindGren, D., W. S. LibBy and F. L. Bondesson (1989): Deployment to plantations of numbers and poportions of clones with special emphasis on maximizing gain at a constant level of diversity. Theor. Appl. Genet. 77: 825-831.

Lindgren, D., L. D. GeA and P. A. JefFerson (1996): Loss of genetic diversity monitored by status number. Silvae Genet. 45: 52-59.

LindGren, D., L. D. GeA and P. A. JefFERson (1997): Status number for measuring genetic diversity. Forest Genetics 4: 1-8.

NiElsen, C. N. and J. K. HANSEN (1999): Functional aspects of root architecture and biomass allocation of six major european forest tree species (Short title "Treearch"). EU contract AIR3-CT93-1269. 299 pp.

O'Neill, G. A., S. N. Aitken and W. T. AdAms (2000): Genetic selection for cold hardiness in coastal Douglasfir seedlings and saplings, Can. J. For. Res. 30 $1799-1807$.
RODRIQUEZ, L. S. (2000): Balanced vs. slightly unbalanced selection. Heredity 84: 685-691.

Ruotsalainen, S. and D. LindGren (1998): Predicting Genetic Gain of Backward and Forward Selection in Forest Tree Breeding. Silvae Genet. 47: 42-50.

SAS Inst. Inc. (1999): SAS OnlineDoc ${ }^{\circledR}$ version eight, SAS Institute Inc., Cary, NC, USA, http://v8doc.sas.com/ sashtml.

Schermann, N., W. T. Adams, S. N. Aitken and J. CH. Bastien (1997): Genetic Parameters of Stem Form Traits in a 9-Year-Old Coastal Douglas-fir Progeny Test in Washington. Silvae Genet. 46: 166-170.

Silen R. R., D. L. Olson and J. C. Weber (1993): Genetic variation in susceptibility to windthrow in young Douglas-fir. For. Ecol. Man. 61: 17-28.

Sit, V. and M. Poulin-Costello (1994): Catalog of curves for curve fitting. Biometrics Information Handbook Series, Handbook No. 4, Ministry of Forests Research Program, Ministry of Forest, BC, Canada. 110 pp.

Spicer, R., B. L. Gartner and R. L. Darbyshire (2000): Sinuous stem growth in a Douglas-fir (Pseudotsuga menziesii) plantation: growth patterns and wood-quality effects. Can. J. For. Res. 30: 761-768.

Stevenson, J. F., B. J. Hawkins and J. H. Woods (1999): Spring and fall cold hardiness in wild and selected seed sources of coastal Douglas-fir, Silvae Genet. 48: 29-34.

Telewski, F. W. and M. J. JAFFE (1986): Thigmomorphogenesis: anatomical, morphological and mechanical analysis of genetically different sibs of Pinus taeda in response to mechanical perturbation. Physiol. Plant. 66: 219-226.

Temel, F. and W. T. Adams (2000): Persistence and ageage genetic correlations of stem defects in coastal Douglas-fir (Pseudotsuga menziesii var. menziesii (Mirb.) Franco). Forest Genetics 7: 145-153.

Vargas-Hernandez, J. J., W. T. Adams and D. G. Joyce (2003): Quantitative Genetic Structure of Stem Form and Branching traits in Douglas-fir Seedlings and Implications for Early Selection. Silvae Genet. 52: $36-44$.

WADA, Y. and N. KASHIWAGI (1990): Selecting statistical models with information statistics. J. Dairy. Sci. 73: 3575-3582.

Wang, T., S. N. Aitken, J. H. Woods, K. Polsson and S. MAGNussen (2004): Effects of inbreeding on coastal Douglas fir growth and yield in operational plantations: a model-based approach. Theor. Appl. Genet. 108: $1162-1171$.

White, T. and G. Hodge (1989): Predicting Breeding Values with Applications in Forest Tree Improvement. Klüwer Academic Publishers, Dordrecht, The Netherlands, $367 \mathrm{pp}$

Woods, J. H., D. Kolotelo and A. YANChUK (1995): Early selection of coastal Douglas-fir in a farm-field test environment. Silvae Genet. 44: 178-186.

Woods, J. H., T. WANG and S. N. AitKen (2002): Effects of inbreeding on coastal Douglas fir: nursery perfomance. Silvae Genet. 51: 163-170.

Woolaston, R. R., P. J. Kanowski and D. G. Nikles (1990): Genetic Parameter Estimates for Pinus caribaea var. hondurensis in Coastal Queensland, Australia. Silvae Genet. 39: 21-28. 